\title{
Dispersion Limit Improvement Of FM/TM Signals By Self-phase Modulation
}

Jørgensen, Carsten Gudmann; Mikkelsen, Benny; Jørgensen, Bo Foged; Pedersen, Rune Johan Skullerud; Stubkjær, Kristian

Published in:

LEOS Summer Topical Meeting on Optical Microwave Interactions/Visible Semiconductor Lasers/Impact of Fiber Nonlinearities on Lightwave Systems/Hybrid Optoelectronic Integration and Packaging/Gigabit Networks

Publication date:

1993

Document Version

Publisher's PDF, also known as Version of record

Link back to DTU Orbit

Citation (APA):

Jørgensen, C. G., Mikkelsen, B., Jørgensen, B. F., Pedersen, R. J. S., \& Stubkjær, K. (1993). Dispersion Limit Improvement Of FM/TM Signals By Self-phase Modulation. In LEOS Summer Topical Meeting on Optical Microwave Interactions/Visible Semiconductor Lasers/Impact of Fiber Nonlinearities on Lightwave Systems/Hybrid Optoelectronic Integration and Packaging/Gigabit Networks IEEE.

\section{General rights}

Copyright and moral rights for the publications made accessible in the public portal are retained by the authors and/or other copyright owners and it is a condition of accessing publications that users recognise and abide by the legal requirements associated with these rights.

- Users may download and print one copy of any publication from the public portal for the purpose of private study or research.

- You may not further distribute the material or use it for any profit-making activity or commercial gain

- You may freely distribute the URL identifying the publication in the public portal 


\title{
LPS1.1 1:30pm-1:50pm
}

\section{Dispersion limit improvement of FM/IM signals by self-phase modulation}

\author{
C.G. Joergensen, B. Mikkelsen, B.F. Jørgensen, R.J.S. Pedersen and, K.E. Stubkjaer \\ Center for Broadband Telecommunications \\ Electromagnetics Institute, Technical University of Denmark \\ Building 348, DK-2800 Lyngby, Denmark \\ Phone: +4542881444 Fax: +45 45931634
}

\begin{abstract}
Simulations of unrepeatered transmission of 10 Gbit/s signals generated by frequency to intensity modulation conversion show an improvement of the dispersion limit on standard fiber due to self-phase modulation by up to a factor of 2.5. This indicates a $1 \mathrm{~dB}$ limit of above $100 \mathrm{~km}$ for optimum modulation index of 0.5 . For this index, simulations indicate the existence of a maximum allowable input power around $+18 \mathrm{dBm}$, above which the channel breaks down. This also applies for dispersion shifted fiber, even at a lower power of around $+14 \mathrm{dBm}$.
\end{abstract}

Introduction. The next generation of optical communication systems will operate at $10 \mathrm{Gbit} / \mathrm{s}$. Generation of optical signals modulated at $10 \mathrm{GHz}$ is difficult: direct on/off keying gives excessive chirping even at small extinction ratios. External Mach-Zehnder amplitude modulators on the other hand tend to require very high modulation voltages. Particularly if the power level is very high, since then balanced push-pull operation is prohibited by Stimulated Brillouin Scattering (SBS). An alternative solution is frequency to intensity modulation (FM/IM) conversion [1], which has the advantages of small modulation voltage and high SBS threshold [2]. Typically the drive voltage to the laser is smaller than $2 \mathrm{Vp}-\mathrm{p}$ and at $10 \mathrm{GHz}$ modulation the SBS threshold (for suitable modulation index) is higher than $20 \mathrm{dBm}$. The dispersion limit of FM/IM signals at $10 \mathrm{Gbit/s}$, however, is quite small [3], dependent on the receiver configuration and the frequency modulation index. This paper gives a theoretical investigation of this limit and the improvement attainable by exploiting non-linear self-phase modulation (SPM). Finally, the maximum allowable input power set by SPM for transmission over both nondispersion shifted and dispersion shifted fiber is considered.

Discussion. The propagation of optical signals on fibers is described by the non-linear Schrödinger equation, which can be numerically investigated using the split-step Fourier transform method [4]. Using this method, we investigate the propagation of a $2^{7}$ long bit sequence, obtained from a $2^{7}-1$ pseudo random binary sequence (PRBS) and adding a logical zero, using 32 samples per bit. The spectrum of the resulting signal resembles that of the PRBS and simultaneously allows simple mathematical handling in terms of Fast Fourier Transform. The receiver bandwidth is $7 \mathrm{GHz}$, using a third order Butterworth filter. Figure 1 shows the simulated eye closure versus transmission distance over non-dispersion shifted fiber $\left(17 \mathrm{psec} / \mathrm{km} / \mathrm{nm}\right.$ dispersion, $80 \times 10^{-12} \mathrm{~m}^{2}$ effective fiber area and $0.2 \mathrm{~dB} / \mathrm{km}$ loss) of a $10 \mathrm{Gbit} / \mathrm{s}$ FM/IM signal, with the average optical input power as parameter for three different modulation indices (linear loss is compensated). It indicates three things: First, that the distance the signals may be transmitted for a given eye closure is increased by up to a factor of 2.5 by increasing the input power; Secondly, whereas the dispersion limit is increased for increasing modulation index at low input power, the dispersion limit is increased with decreasing modulation index for high input power; Finally, the figure indicates the existence of a maximum allowable input power, above which the channel breaks down.

This breakdown also exists on dispersion shifted fiber $\left(1.6 \mathrm{psec} / \mathrm{km} / \mathrm{nm}, 40 \times 10^{-12} \mathrm{~m}^{2}\right.$ and $\left.0.2 \mathrm{~dB} / \mathrm{km}\right)$. Figure 2 shows the simulated eye closure vs. transmission distance for $10 \mathrm{Gbit} / \mathrm{s}$ transmission over dispersion shifted fiber of a FM/IM signal using a modulation index of 0.5 . Obviously, with an input power of $10 \mathrm{dBm}$, a $10 \mathrm{Gbit} / \mathrm{s} \mathrm{signal} \mathrm{can}$ not be received after $300 \mathrm{~km}$ since the input power would be around $-50 \mathrm{dBm}$, which is far below the best reported sensitivity of $-38.8 \mathrm{dBm}$ [5]. That would require $+22 \mathrm{dBm}$ transmitted power, which as mentioned above is possible from an SBS point of view. However, for input powers in that range, the transmission distance is limited by SPM, as seen from figure 2 . Hence it seems as if $300 \mathrm{~km}$ unrepeatered transmission at $10 \mathrm{Gbit} / \mathrm{s}$ is not possible. From the simulations, the limit is around $250 \mathrm{~km}$ for an input power of $+13 \mathrm{dBm}$, as seen from figure 3 .

Conclusion. Simulations indicate an increase up to 2.5 times of the dispersion limit of FM/IM signals by self-phase modulation for $10 \mathrm{Gbit} / \mathrm{s}$ signals transmitted over standard fiber. They also show, that the modulation index should be low when using high input powers, and finally, that there is a maximum allowable input power, above which 
the channel breaks down. For dispersion shifted fiber a breakdown seems to exist at $+14 \mathrm{dBm}$, limiting the maximum unrepeatered transmission distance of $10 \mathrm{Gbit} / \mathrm{s}$ signals to around $250 \mathrm{~km}$ (for assumed parameter values).

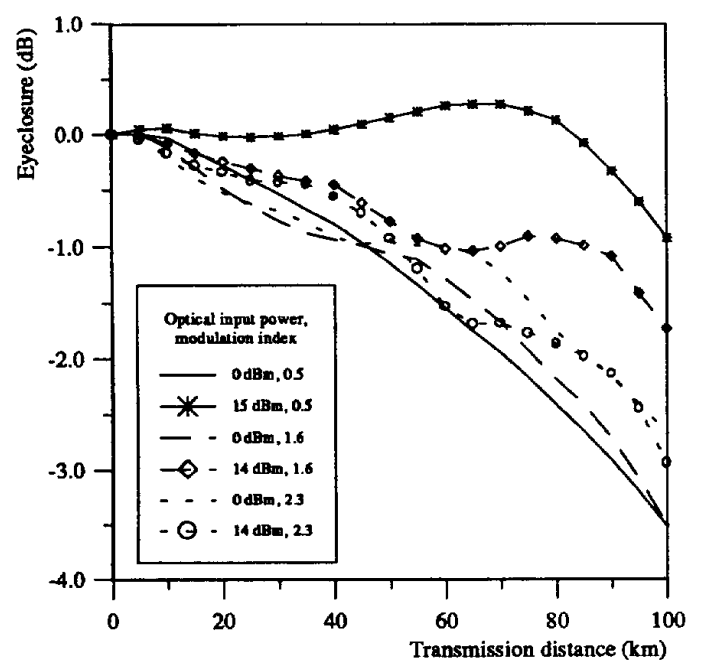

Figure 1a. Eye closure relative to back-to-back signal as function of transmission distance for optimum (within $1 \mathrm{~dB}$ ) input power for modulation indices of $0.5,1.6$ and 2.3 .

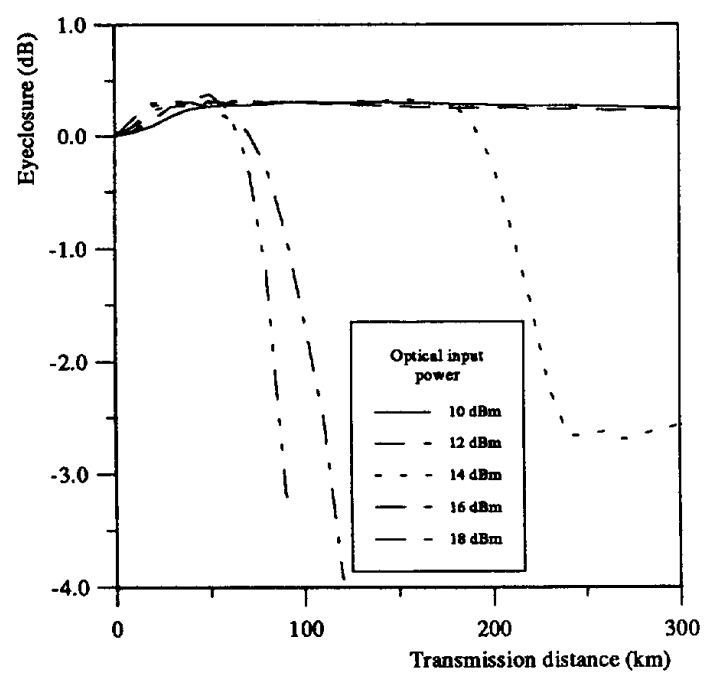

Figure 2. Eye closure relative to back-to-back signal as function of transmission distance for a modulation index of 0.5 with optical input power as parameter for transmission over dispersion shifted fiber.

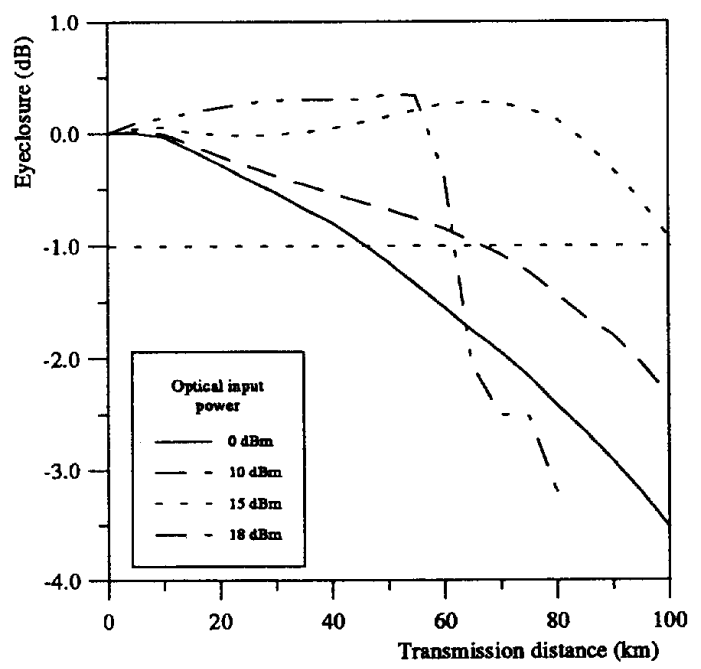

Figure $1 b$. Eye closure relative to back-to-back signal as function of transmission distance for modulation index of 0.5 with optical input power as parameter.

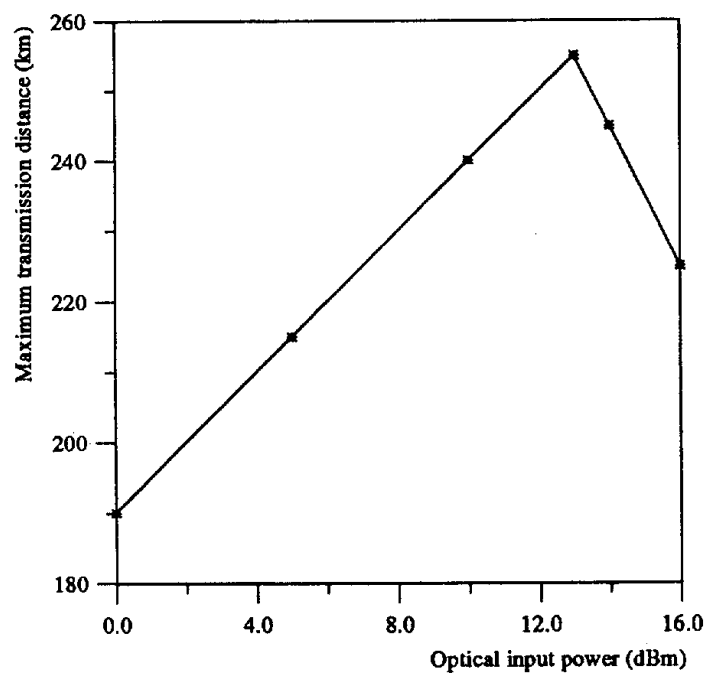

Figure 3. Maximum transmission distance for 10 Gbit/s FM/IM transmission over dispersion shifted fiber assuming receiver sensitivity of $-\mathbf{3 8 . 8} \mathrm{dBm}$.

References.

[1] E.G. Bryant et al., Electron. Lett., vol. 26, no. 8, April 1990, pp528-529

[2] T. Sugie, J. Lightwave Technol., vol. 9, no. 9, September 1991, pp 1145-1155

[3] A.F. Elrefaie et al IEEE Photon. Technol. Lett., vol. 3, no. 1, January 1991, pp. $71-73$.

[4] G.P. Agrawal, Nonlinear Fiber optics, San Diego: Academic Press 1989

[5] R.I. Laming et al, PD13, Optical Amplifiers and Their Applications, Santa Fe 1992 